\title{
¡URGENTE EDUCACIÓN PARA EL CONSUMO! CASO: TARJETAS DE CRÉDITO COMPARTIDAS ENTRE ESTABLECIMIENTOS DE COMERCIO Y ENTIDADES BANCARIAS
}

\author{
Elaborado por: Sara Catalina Forero Molina \\ Samir Ricardo Neme Chaves
}

El uso de tarjetas de crédito se ha convertido en un tema relevante en el mundo hoy en día, esto debido a que la facilitación del consumo ha llevado a comprar menos por necesidad, y más por emocionalidad y el gusto momentáneo, perjudicando las finanzas de las personas, al no regular la estructura de gasto ni a mantenerla dentro de parámetros razonables y conformes con la estructura de ingreso de las personas.

Se ha encontrado, adicionalmente, que existen factores de conducta o personalidad que asocian la utilización de ese medio de pago con una conducta de mayor displicencia (Garzón \& Sánchez, 2017), teniendo en cuenta entre otras que hay una falsa idea que es un producto "gratis" ya que su costo solo se va a ver reflejado en el futuro, lo que hace que las consecuencias de la compra se vean solo 30 días después en el extracto de la tarjeta.

Además de una aceptación social del endeudamiento que ha hecho que cada vez más personas accedan a créditos de este tipo, principalmente por los beneficios adicionales de estas tarjetas (Garzón \& Sánchez, 2017) como son descuentos si se compra en días específicos o no cobro de cuota de manejo si se mantiene un número mínimo de compras a lo largo del mes lo que lleva finalmente a mantener un uso no razonable de la tarjeta. 
Estos comportamientos de compra impulsivos y poco mediados por una decisión tranquila y suficientemente pensada se ve en diferentes productos, pero especialmente en los que el cliente tiene la percepción de perder la última oportunidad para tenerlos en su poder, como por ejemplo y sobre todo las ofertas por tiempo limitado (Morales, 2007).

Por otro lado, se ha visto que hay productos relacionados con una gran carga hedónica (con pocas características objetivamente funcionales) respecto a otro producto similar, pero que la persona prefiere por su vinculación emocional con el mismo, por ejemplo los juegos de videos como el fifa 19 que el consumidor necesita poseer no porque sea extremadamente distinto a su versión inmediatamente anterior (cambiarán algunos jugadores de equipo, o nuevas equipaciones de los equipos pero objetivamente el fifa 18 es igual al fifa 19), sin embargo es un producto que hace sentir bien al consumidor al poseer su ultima versión y estar "en el curubito" del juego, porque el fifa 18 ya no vale la pena, para los consumidores.

Por ende, el juego de las tarjetas de crédito en las que se terminan involucrando los consumidores, muchas veces de manera irracional, crece exponencialmente en nuestro contexto. Así, hoy en día las tarjetas de crédito de marca compartida entre establecimientos de comercio y entidades bancarias o también conocidas como tarjetas de crédito de marca propia se han venido popularizando, pero ¿qué son estas tarjetas?. $\mathrm{Al}$ respecto es preciso aclarar que se trata de tarjetas de crédito que bajo el principio de alianza tienen como pretensión la obtención de beneficios para tres actores: (a) establecimiento comercial por la oportunidad de aumentar las ventas y generar lealtad, (b) cliente por la posibilidad de obtener crédito en el establecimiento de su preferencia y beneficios adicionales como descuentos, acumulación de puntos, reducción en cuotas 
de manejo, entre otros, y (c) entidad bancaria por aumentar la usabilidad de las tarjetas en compras concretas y definidas sobre las que se tiene una previa preferencia.

Este tipo de tarjetas tuvieron como banco pionero en Colombia a Colpatria hacia los años 90, el cual para 2017 se posicionó como el segundo emisor de éste tipo de productos con 2.3 millones de plásticos (Quintero, 2017). También es preciso destacar que en lo referente a éste tipo de tarjetas enfocadas en el sector de la moda, Colombia es el tercer país de la región con mayor uso de éstos plásticos (1.8 millones) antecedido por México (3 millones) y Brasil (3.5 millones) (López, 2017). Algunos ejemplos de alianzas vigentes incluyen Davivienda con Avianca, Banco de Bogotá con Andrés Carne de Res, Banco de Occidente con Bodytech, Colpatria con Directv, entre otras.

Lamentablemente, así como traen beneficios, su uso inadecuado trae efectos negativos y riesgos para los usuarios sobre todo si se entiende que como indica Oliveros (citado por López, 2017), muchas personas al poseer una de éstas tarjetas de crédito de marca compartida sienten la tentación del consumo.

Todo lo expuesto implica la importancia y urgencia de la educación para el consumo en torno al uso de las tarjetas de crédito de marca compartida. Al respecto se han hecho algunas recomendaciones como la de Barragán (s.f., citado en Puentes, 2014) en cuanto a que "hay que procurar afiliarse a la tarjeta que tenga asociación con el sector consumo donde invierta la mayor parte de sus ingresos, es decir que debe perfilar sus necesidades para que de esta manera no corra el riego de cometer errores financieros como puede ser un sobrendeudamiento". 
De igual manera, éste tema se inserta en los programas de educación financiera que se trabajan en el país y en los que participan diversas entidades como la Superintendencia Financiera de Colombia, Asobancaria, el Ministerio de Educación Nacional, entre otros, además de bancos, colegios y universidades. Así, recogiendo algunas recomendaciones en cuanto al adecuado uso de las tarjetas de crédito presentes en diferentes programas y cartillas de educación de las entidades se destacan:

- Es importante informarse siempre y comparar dentro de las opciones en el mercado para elegir la más conveniente en términos de la capacidad de pago y las necesidades reales.

- No haga uso de la tarjeta de crédito si no tiene claridad y seguridad de que puede pagar.

- Seguir las recomendaciones de seguridad para evitar robos y fraudes.

- No adquiera una cantidad de tarjetas de crédito que excedan su capacidad de cumplimiento

- Programar los pagos a realizar y mantener una planeación de gastos actualizada

Para finalizar, es importante dejar como reflexión la importancia de ver la educación para el consumo adecuado de éstas tarjetas de crédito de marca compartida como algo que amerita la responsabilidad desde muchos frentes, es decir, no basta con que a nivel gubernamental se asuma la urgencia y las acciones si no se infunde lo respectivo desde la unidad básica de la sociedad como es la familia. También es importante y hace parte de la responsabilidad y obligación de los establecimientos comerciales, sin embargo, a la fecha no se ve un trabajo constante y enfocado por parte de éstos. 


\section{Referencias}

Garzón, M. y Sánchez, N. (2017). Características de personalidad y el comportamiento de compra impulsiva a partir del uso y consumo de tarjetas de crédito propias y compartidas que brindan los hipermercados en mujeres entre los 25 y 35 años de estratos 2,3, 4 de la ciudad de Bogotá. (Tesis de grado). Disponible en: http://repository.usta.edu.co/bitstream/handle/11634/3164/Sancheznatalia2017.pdf?se quence $=1 \&$ is Allowed $=\mathrm{y}$

López, J. (2017). Tarjetas de crédito de marca propia aumentan en las tiendas de moda. Recuperado el 2018, de Sitio web de La República: https://www.larepublica.co/finanzas-personales/tarjetas-de-credito-de-marcapropia-aumentan-en-las-tiendas-de-moda-2514461

Morales, F. (2007) Psicología Social. Mac Graw Hill (3ed). España.

Puentes, J. (2014). Davivienda y Colpatria son las entidades financieras con más tarjetas compartidas. Recuperado el 2018, de La República: http://www.larepublica.co/davivienda $\neg$ y $\neg$ colpatria $\neg$ son $\neg$ las $\neg$ entidades $\neg$ financ ieras $\neg$ con-m\%C3\%A1s $\neg$ tarjetas $\neg$ compartidas_125586

Quintero, A. (2017). La guerra de beneficios de las tarjetas de crédito se expandió a los ecuperado el 2018, de La República: http://www.larepublica.co/la-guerra-debeneficios-de-las-tarjetas-de-cr\%C3\%A9dito-se-expandi\%C3\%B3-losretailers_483361 


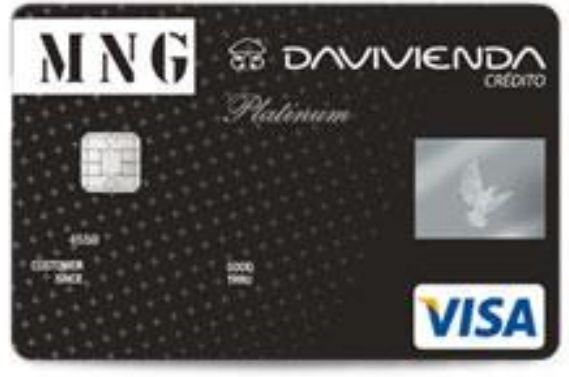

Fuente: Sitio web https://shop.mango.com/co/mujer/help/2894.html

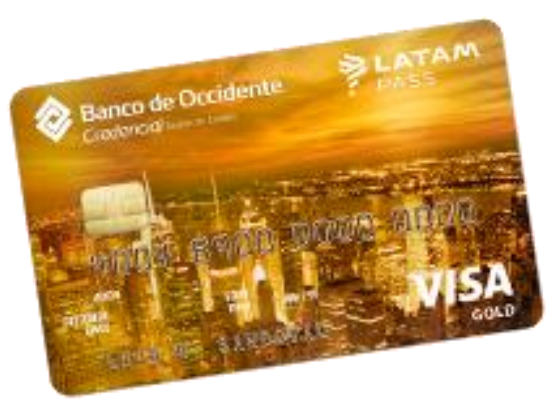

Fuente: Sitio web https://www.bancodeoccidente.com.co/wps/portal/banco-deoccidente/bancodeoccidente/para-personas/tarjeta-de-credito/nuestras-tarjetas

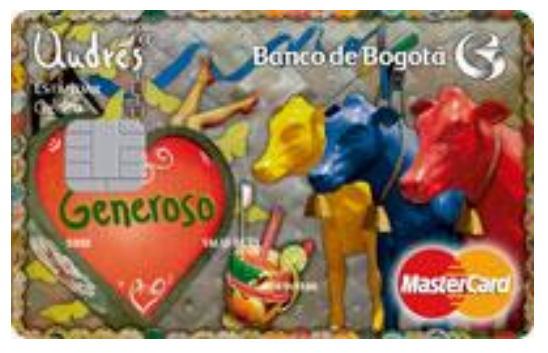

Fuente: Sitio web https://www.bancodebogota.com/wps/portal/banco-debogota/bogota/productos/para-ti/tarjetas-de-credito/tarjeta-andres-carne-de-res$\underline{\text { estandar }}$ 
